\title{
AUDITORIA INTERNA COMO INSTRUMENTO DE ADEQUAÇÃO APLICADO NO ESTOQUE DE UMA INDÚSTRIA DA CIDADE DE MANAUS-AM
}

\section{ARTIGO ORIGINAL}

FERREIRA, Vitória Moura ${ }^{1}$, BRITO, Carlos Victor de Castro $^{2}$, SEVALHO, Felipe Valério ${ }^{3}$, CAMPOS, Gabriel Andrade ${ }^{4}$, ROBERTO, José Carlos Alves ${ }^{5}$, SERRA, Meg Rocha da Cunha ${ }^{6}$, LOPES, Nelânia Ferreira ${ }^{7}$

FERREIRA, Vitória Moura. Et al. Auditoria interna como instrumento de adequação aplicado no estoque de uma indústria da cidade de Manaus-AM. Revista Científica Multidisciplinar Núcleo do Conhecimento. Ano. 06, Ed. 11, Vol. 05, pp. 48-86. Novembro 2021. ISSN: 2448-0959, Link de acesso: https://www.nucleodoconhecimento.com.br/contabilidade/instrumento-de-adequacao, DOI: 10.32749/nucleodoconhecimento.com.br/contabilidade/instrumento-deadequacao

\section{RESUMO}

Tendo em vista que os estoques são percebidos como recursos econômicos que asseguram 0 processo produtivo, este estudo buscou abordar sobre a seguinte questão norteadora: Qual a importância da utilização da auditoria interna de estoques para a realização do controle interno, diante da falta de um controle integrado no setor de almoxarifado em uma indústria do polo industrial da cidade de

\footnotetext{
${ }^{1}$ Graduanda do curso de Ciências Contábeis.

${ }^{2}$ Graduando do curso de Contabilidade.

${ }^{3}$ Graduando do curso de contabilidade.

${ }^{4}$ Graduando do curso de contabilidade.

${ }^{5}$ Orientador. Mestre em Engenharia de produção. Especialista Logística empresarial. Graduado em Administração com Ênfase em Marketing.

${ }^{6}$ Orientadora. Mestra em Engenharia de Processos Industriais pela UFPA, especialista em Controladoria e Auditoria Contábil pelo Ciesa, Graduada em Ciências Contábeis pelo Centro Universitário do Norte. Graduada em Ciências Econômicas pelo Centro Universitário do Norte.

${ }^{7}$ Orientadora. Especialista em Auditoria Contábil, Financeira e Tributaria e Graduada em Ciências Contábeis.
} 
Manaus-AM? Esta temática tem como objetivo geral analisar a adequação do controle de estoque em uma indústria do polo industrial da cidade de Manaus-AM a partir da realização da auditoria interna. A metodologia utilizada para a construção desta pesquisa, classifica-se como descritiva, qualitativa e aplicada, desenvolvida a partir de um estudo de caso realizado em uma indústria do polo industrial que atua na fabricação de televisores e, atualmente, possui em média 1000 funcionários. Através deste estudo de caso, pode-se constatar que a empresa possui falhas nos controles internos no setor de almoxarifado, para o qual foi desenvolvida a proposta de melhoria, a partir da realização da auditoria interna e da implantação de gestão do sistema $A B C$ no estoque. Assim, entre os principais benefícios alcançados, estão a redução dos custos operacionais, diminuição dos desperdícios, melhoria no atendimento aos clientes e, consequente aumento das vendas dos televisores. Sendo que as propostas de melhorias sugeridas à empresa, ainda estão sendo avaliadas pelos gestores. Conclui-se, portanto, que a auditoria interna é uma ferramenta que possibilita a identificação, previsão e solução de problemas, através da assessoria e análise correspondente às necessidades da indústria do polo industrial.

Palavras-chave: Estoque, Indústria do Polo Industrial, Controle Interno, Sistema ABC.

\section{INTRODUÇÃO}

Considerando que as organizações se reinventam e utilizam estratégias para se destacar no mercado, as elaborações de métodos de controle interno tornam a organização mais estruturada e de fácil monitoramento, refletindo consideravelmente na qualidade do produto e, principalmente, no crescimento dos lucros. Com o desenvolvimento da contabilidade para o contexto administrativo, esses métodos passaram a ser mais ágeis, dado que dispõem de padrões que possibilitam uma adequada administração (LIMA, 2021).

RC: 100860

Disponível em:

https://www.nucleodoconhecimento.com.br/contabilidade/instrumento-de-adequacao 
Foi identificado a partir da coleta de dados, observação e análise de documentos da indústria do polo industrial, que a mesma possui uma deficiência no setor de almoxarifado quanto a falta de um controle integrado no estoque, no que se refere ao recebimento e armazenamento dos produtos, pois, é realizado de forma manual a contagem das mercadorias, para em seguida, desenvolver a verificação da nota fiscal, o que acaba atrasando os serviços pela perda de tempo na execução da atividade.

Deste modo, o tema da pesquisa apresentada propõe a seguinte pergunta problema: Qual a importância da utilização da auditoria interna de estoques para a realização do controle interno, diante da falta de um controle integrado no setor de almoxarifado em uma indústria do polo industrial da cidade de Manaus-AM?

Este estudo tem como objetivo geral analisar a adequação do controle de estoque em uma indústria do polo industrial da cidade de Manaus-AM a partir da realização da auditoria interna. E como objetivos específicos, descrever o controle interno a ser utilizado no estoque pela organização e comparar o sistema de estoque atual com o que pode ser aplicado.

Portanto, percebe-se que o contexto apresentado se caracteriza como um relevante assunto, que possui grande valia pessoal, acadêmica, científica e profissional, em virtude de essa temática ser de interesse comum. Pela auditoria interna exercer importante papel no mapeamento das atividades e no controle de estoque, e se apresentar como um, mas relevante método interno das organizações.

A metodologia utilizada para a construção desta pesquisa de campo e bibliográfica, classifica-se como descritiva, qualitativa e aplicada, realizada a partir de um estudo de caso em uma indústria do polo industrial que atua na fabricação de televisores.

Espera-se que a indústria desenvolva a auditoria interna, a fim de identificar possíveis falhas, estruturar melhor o seu estoque e se tornar mais competitiva no mercado. Dado que a auditoria interna é fundamental para a investigação dos métodos internos das empresas.

RC: 100860

Disponível em: 


\section{FUNDAMENTAÇÃO TEÓRICA}

A fundamentação teórica é a parte da pesquisa que apresenta os contextos relevantes a serem abordados no trabalho. Os assuntos servirão como fundamento para a construção da problemática abordada no mesmo. Sendo assim, é indispensável produzir o referencial teórico embasado em autores que orientam o estudo, o qual, comumente, vem separado por tópicos que apresentam os conceitos relacionados ao problema apresentado (DIAS, 2020).

\subsection{DEFINIÇÃO DE AUDITORIA}

A expressão auditoria é originada do latim audire (ouvir). Os ingleses utilizavam esse vocabulário para apresentar os procedimentos técnicos na revisão da contabilidade. No Brasil, as primeiras reflexões sobre auditoria ocorreram com a colonização dos portugueses, sendo exercidas por um profissional habilitado de conhecimentos e técnicas, a fim de apresentar um controle mais eficiente nas finanças (MELLO e SANTOS, 2017).

A partir da Revolução Industrial várias empresas começaram a expandir suas atividades para além das fronteiras, o que gerou a necessidade de um melhor monitoramento e controle. Isso contribuiu para que os sócios acompanhassem de perto todos os procedimentos, tornando-se importantes profissionais, com comportamentos éticos e conhecimentos técnicos, que transmitissem opiniões acerca das transações realizadas pela organização e, com isso, surgiu a figura do auditor como se conhece atualmente (MAFFEI, 2015).

O objetivo da auditoria, enquanto um conjunto de procedimentos, é averiguar e adequar a efetividade dos controles, bem como revisar as operações das organizações, para analisar se a mesma se enquadra às normas pertinentes. Por isso, compreende a análise de documentos, livros e registros; inspeções e obtenção de informações; e confirmações, internas e externas, relacionados com o controle do 
patrimônio, com o propósito de mensurar a exatidão das demonstrações contábeis e dos registros decorrentes (MOREIRA, 2018).

Segundo Araldi (2019), pode-se perceber que, comumente, o objetivo da auditoria é assegurar que as empresas estejam conforme as normas da contabilidade. Logo, a auditoria se limitou inicialmente à atividade de examinar as demonstrações contábeis com o objetivo de observar se realmente elas emitem a real condição patrimonial do empreendimento, para dar maior credibilidade à mesma.

Observa-se que o termo auditoria é bastante utilizado nas várias áreas, como a área da educação, saúde, dentre outras, e isso pode estar relacionado aos conceitos de transparência e responsabilidade, uma vez que a auditoria desenvolve um papel estratégico e de responsabilidade social quando pode promover a transparência das demonstrações financeiras. Sendo assim, a implantação de um departamento de auditoria deve seguir os padrões de valores conforme sua competência (NASCIMENTO, 2020).

\subsection{AUDITORIA INTERNA}

Segundo Lima (2011), a auditoria interna possui importante função na mensuração do desempenho, prestação de contas e no sistema de dados da empresa, aplicando padrões éticos, técnicos e diretrizes. A auditoria interna está desenvolvendo e alcançando valorização nas empresas, auxiliando no processo de decisão da gestão e promovendo estratégias modernas para controles internos. O que tem tornado as empresas mais competitivas e sólidas.

A auditoria iniciou-se a partir do desenvolvimento do sistema capitalista, promovendo o avolumamento do mercado. Com a evolução das empresas surgiu a necessidade de realizar demonstrações contábeis seguras, para que futuros acionistas e investidores alcançassem colocações financeiras e patrimonial de destaque nas empresas (ALMEIDA, 2010).

RC: 100860

Disponível em:

https://www.nucleodoconhecimento.com.br/contabilidade/instrumento-de-adequacao 
A auditoria diz respeito a uma avaliação diária de processos, planos e transações de uma empresa, feita através do uso de metodologias com o objetivo de fornecer um Relatório de Auditoria Independente (RAI) relacionado às adaptações e mecanismos. Em outras expressões, a auditoria visa verificar se as demonstrações contábeis estão livres de divergências, considerando as perspectivas econômicofinanceiras e patrimoniais das organizações (PEPINELLI et al., 2011).

Pode-se afirmar que a auditoria surgiu devido à necessidade de os investidores verificarem se as evidências refletem na existência patrimonial da companhia. $O$ papel da auditoria é identificar se os indicadores contábeis estão livres de alterações. Assim, estes dados são utilizados pela própria empresa auditada, por administradores, investidores ou terceiros destituídos do empreendimento, como: bancos, órgãos governamentais e sociedade (ALMEIDA, 2012).

Dividida em várias etapas, a auditoria pode determinar todas as fases a serem seguidas, baseados em normas e condutas. Com isso, os processos de auditoria podem ser definidos como métodos utilizados pelo auditor para alcançar dados necessários, a fim de emitir opinião acerca dos relatórios contábeis. Para conquistar o objetivo determinado e emitir o relatório, o auditor necessita realizar o planejamento de todo o trabalho, revisando controles internos, analisando as contas do balanço patrimonial, dentre outros (LÉLIS e PINHEIRO, 2012).

\subsection{CONCEITOS DE INDUSTRIAIS}

Araújo et al. (2020) conceituam os processos industriais como um conjunto de operações realizadas em um determinado período para poder gerar, fabricar ou transformar uma elevada quantidade de produtos. Atualmente, nas indústrias, as empresas estão sempre buscando melhorias constantes em seus processos produtivos, para geração de qualidade, produtividade, menor custo e alta eficácia. As empresas que vivem atuando nesse ramo industrial reagem conforme o crescimento tecnológico, apresentando ao mercado empresarial, produtos com alta qualidade.

RC: 100860

Disponível em:

https://www.nucleodoconhecimento.com.br/contabilidade/instrumento-de-adequacao 
Através dos processos industriais, é possível aproveitar ao máximo os recursos naturais utilizados para gerar produtos e, logo, transformar os produtos em ferramentas importantes e adequadas, que possam atender as necessidades dos clientes. Sendo assim, o desenvolvimento do consumo de produtos industrializados e da globalização dos mercados vem aumentando, exigindo investimento na indústria, em virtude da competitividade, sendo o grande diferencial do processo industrial a produção dos produtos com alta qualidade (HERMES, 2020).

Esses processos industriais ainda esperam atingir um objetivo maior que se baseia em conquistar grande número de benefícios. Por isso, o planejamento para criar valores está relacionado ao desempenho da empresa, envolvendo todos os funcionários, a fim de trabalharem com foco na satisfação do cliente. Logo, para conquistar um bom desempenho no setor produtivo industrial, é necessário estabelecer bons processos grupais que orientem o líder e o liderado à solução dos problemas (SOUSA e COSTA, 2020).

O processo industrial é um diferencial no alcance produtivo da equipe ou ainda na prevenção dos conflitos entre os colaboradores. No processo produtivo industrial, a atuação, o clima e o comportamento do liderado, ocorre segundo o tipo de liderança realizada pelo líder do setor, pois suas atitudes vão refletir na equipe, seja de maneira positiva ou negativa (WENDLING, 2017).

$\mathrm{Na}$ denominada modernidade, o processo industrial foi se aperfeiçoando cada vez mais conforme a inserção da tecnologia no chão de fábrica, influenciada pela utilização do excesso de dados digitalizados, das diversas redes de comunicação e do crescente desenvolvimento no poder de processamento computacional. Assim, dado esse aperfeiçoamento, atualmente, o processo industrial possui uma quantidade elevada de aparelhos sofisticados (COLUSSI e HANGAI, 2015).

Portanto, o setor industrial se apresenta como importante fonte econômica para qualquer país, e seus reflexos na economia atingem de forma direta o desenvolvimento mundial. Nos últimos anos, as mudanças ocorreram no chão de 
fábrica, tanto no cenário da inovação tecnológica, quanto nos conceitos organizacionais, já projetados para o futuro. São setores onde todo o processo é desenvolvido sem interferência humana, mas, com máquinas de última geração, em que o operador somente supervisiona o processo por meio da tela de computadores (COSTA e STEFANO, 2014).

\subsection{CONCEITO DE ESTOQUE}

De acordo com Lima (2021), os estoques são suprimentos e materiais que uma empresa possui para produzir produtos ou atender às suas próprias necessidades. Desta forma, o controle de estoque permite que a empresa administre e analise se seus estoques estão sendo aplicados, manejados e organizados corretamente conforme os setores que os utilizam. Nesse ambiente, os materiais possuem valor econômico por representarem investimentos voltados às atividades de produção.

Todas as concentrações geradas nos estoques são recursos materiais que, processados ou não, se mantêm em um sistema. É perceptível que as empresas investem, visando terem resultados positivos, para futuramente continuar sobrevivendo nos negócios, independente do seu porte. O estoque atua como gerador de crescimento da demanda que pode ser usado pela empresa, fornecendo produtos que estejam prontos e disponíveis no momento que o cliente desejar (CAMPAGNARO, 2019).

Os estoques são ativos que possibilitam economias na produção, assim como, normalizam as diferenças de ritmos entre os fluxos de uma empresa. Devido à necessidade do fluxo financeiro, o estoque é o capital contabilizado, como parte do capital da instituição, e para garantir melhor resultado, é necessário ter a organização dos produtos, permitindo que os estoques sejam geridos de forma correta, e que todos os itens sejam cuidados de forma semelhantes numa empresa (SILVA e LOOS, 2016). 
Segundo Gasnier et al. (2018), para que ocorra a organização dos itens em um estoque, é preciso que o processo de classificação seja seguido, em virtude da elevada diversidade. De fato, o mercado exige muito das empresas e para atender ao mercado com produtos de qualidade, o estoque demanda organização. Por isso, a gestão de estoque necessita de administração eficiente, para diminuir o desnivelamento entre o fornecimento e a busca de forma econômica viavelmente.

Os estoques representam um importante investimento de capital, deste modo, a capacidade de geração de negócios e lucros precisa de organização, através do planejamento correto para ocorrer uma comunicação ativa. Sendo o estoque um item físico representado por um produto final que ainda não passou pela saída ou matéria-prima e insumos que ainda não foram utilizados para produção, este sempre deve estar preparado para ser utilizado. Sua cadeia de suprimento é fundamental na organização dos produtos (MARTINS e CONCEIÇÃO, 2019).

\subsubsection{TIPOS DE ESTOQUE}

Para Martelli (2015), atualmente, o estoque encontra-se localizado em todo o processo de produção de uma organização. Isso ocorre desde a compra da matériaprima, até a disponibilidade do produto para a venda, o que torna necessário gerir os produtos com competência, por meio de ferramentas ou técnicas utilizadas pelos administradores de estoque com o propósito de agregar valor ou capital à empresa. Sendo assim, nas empresas existem alguns importantes tipos de estoques que são: produtos acabados, matéria-prima e produtos em processo.

O estoque de matéria-prima tem a função de estocar e incorporar o produto acabado nos sistemas de estoque, em que todo o consumo é viável na capacidade da produção. Embora esses produtos sejam comprados ou recebidos, ainda não passaram pelo sistema de entrada da produção, sendo a organização dos documentos relacionados mantidos na espera (SENNE e UCHOA, 2019).

RC: 100860

Disponível em:

https://www.nucleodoconhecimento.com.br/contabilidade/instrumento-de-adequacao 
As organizações devem se atentar aos diversos tipos de estoques, uma vez que eles são importantes para a atividade de qualquer trabalho. Para isso, existe um processo de controle a ser empregado, que objetiva reduzir investimentos nos estoques, visando as necessidades da organização, a fim de atendê-las de forma suficiente. Logo, é vital ter o escopo da importância do entendimento funcional do setor moderno da empresa, pois, esta consciência interfere de forma invasiva nos resultados que a organização pretende alcançar (SILVA et al., 2019).

Cada funcionário da empresa pode ter acesso ao setor de estoque. Quando necessário, cada técnico tem autorização para retirar as peças necessárias e, assim, dar continuidade ao atendimento que está sendo desenvolvido. O controle de saída de itens do estoque, é precisamente monitorado. Cada peça retirada do estoque é registrada no caderno de controle, onde consta também a data, o nome do cliente e qual técnico prestou o atendimento no controle do estoque, cujo objetivo é otimizar o investimento no estoque (ZGIERSKI, 2016).

Diante de muitas mudanças existentes, os tipos de estoque possuem importantes funções que demandam aprimoramento para não comprometerem o capital da empresa, ou seja, o lucro. Todo estoque, saindo em alta quantidade, deve ser analisado, com a possibilidade de disponibilizar elevados descontos. Desta forma, o setor do estoque deve estar em excelentes condições, sempre preparado para agregar valores, atendendo sua demanda no tempo certo (ROCHA, 2019).

\subsubsection{ESTOQUES DE INSUMOS}

Os insumos correspondem a todo tipo de matéria-prima, ou outros materiais, que estão estocados ou armazenados nas empresas, esperando o processo de produção. (PORTAL EDUCAÇÃO, 2013).

Essa categoria de estoque, pelo qual se espera chegar na linha de produção, representa custo para a empresa, por esse motivo, os cuidados são importantes para não afetar de forma direta o caixa da empresa (MARQUES, 2010). 
Nesse tipo de estoque, os itens são obtidos junto aos fornecedores e são armazenados em estoque. Desta forma, a empresa pode minimizar as suas perdas, causadas pela falta de produção ou por outros fatores, e aproveitar todas as oportunidades que surgirem. Assim, é fundamental enfatizar que essa organização contribui com o investimento de capital, e logo, alcança o ativo do empreendimento (MANGONI, 2014).

Uma administração de materiais nos padrões, pode prevenir possíveis problemas e ainda os existentes (ZGIERSKI, 2016).

Para Zorzo (2015), uma boa organização contribui com um serviço de qualidade dos insumos produtivos, podendo se integrar com outras áreas, armazenando e desempenhando um papel importante na gestão dos estoques. É importante definir o local exato dos insumos, para garantir que o armazenamento seja ideal, e analisar assuntos de retirada e transporte, a fim de garantir que os produtos estejam prontos para saída, sem a ocorrência de problemas.

O que também se considera, são as decisões tomadas visando estar mais próximo da produção, permitindo um diálogo rápido entre todos da equipe, assim como toda a operação entre os mesmos. Com isso, a organização terá grande sucesso em seus resultados no tempo em que existir uma maior integração entre os profissionais envolvidos, pois, os insumos desenvolvem funções, junto a outros tipos de processos e regimes envolvidos pela empresa (COSTA et al., 2020).

\subsubsection{ESTOQUE DE PRODUTOS EM ELABORAÇÃO}

O estoque de produtos em elaboração exige a organização dos produtos em desenvolvimento, das matérias-primas, mercadorias, materiais de consumo, dentre outros serviços. No decorrer do processo de produção, são armazenados, nesse tipo de estoque, componentes e produtos que estão em processo de produção ou que serão fabricados. Existe possibilidade, devido cada método de fabricação ser 
formado por etapas, em que algumas são complexas, dependendo de um produto final (PORTAL EDUCAÇÃO, 2013).

É importante afirmar que o estoque de produtos em elaboração deve passar por um procedimento de organização, estes são definidos como todos os produtos que no fechamento do balanço, ainda se concentram na espera para produção, representando custos aplicados. Sendo assim, de fato, as empresas precisam manter os cuidados e as estratégias, indispensáveis para a sobrevivência da indústria no mercado atual (PACHECO, 2014).

Os produtos que se encontram em processo de elaboração, relativamente acabados, estão em uma posição intermediária no processo produtivo e precisam ser mantidos com total qualidade. Todo estoque representa custos em seu processo, e é por isso que cada etapa de produção ou aquisição possui uma porcentagem de custos de armazenagem (POZO, 2010).

Produtos em elaboração devem ter controle não custo de falta, sempre deve passar pela manutenção para compreender se a quantidade é suficiente para atender ao processo, evitando causar a interrupção do mesmo. Todo esse cuidado, é para prevenção em custos por vendas perdidas, atraso na entrega e ociosidade, contudo, o estoque de elaboração de materiais deve ser desenvolvido, sempre pensando nos impactos que podem ocorrer no processo, sem gerar custos agressivos (PYKE et al., 2017, p. 533).

Para ocorrer uma organização dos itens fechados para balanço, é necessário passar pela etapa de produção, sempre seguindo as normas dos custos e orçamentos. Essas informações surgem do processo produtivo, onde cada um realiza as orientações de forma independente, mas seguindo os padrões de qualidade. Assim, todo valor de venda dos materiais possui descrição e percentual calculado sobre tudo que sai e entra no estoque, e principalmente, dos produtos em elaboração, gerando, com isso, custos mínimos de estoques no sistema produtivo (PUCHKOVA et al., 2016). 


\subsubsection{ESTOQUE DE PRODUTOS ACABADOS}

Atualmente, as empresas buscam continuamente se destacar no mercado, utilizando da melhor forma suas ferramentas para explorar a positividade em seu processo produtivo. Para que uma organização seja eficiente nos estoques, é necessária uma boa administração que compreenda tudo sobre esse setor, de modo a direcionar esses recursos de forma estratégica. Uma boa administração de estoques contribui para a resolução de problemas financeiros relacionados à materiais, sejam eles matérias-primas, materiais em produtos acabados e em processos (PIRES, 2016).

Os produtos acabados formam o principal tipo de mercadorias em estoques, posto que, são os materiais que já passaram pelo processo produtivo e estão à disposição do mercado consumidor. Basicamente, esse é o principal tipo de estoque utilizado pelas indústrias. Logo, os estoques exercem papel determinante nos custos e nos serviços de uma empresa (PORTAL EDUCAÇÃO, 2013).

Por isso, é necessário a elaboração de um planejamento, realizado principalmente para obter o controle dos materiais, a fim de prevenir impactos financeiros, promovendo melhor eficiência nas ações da empresa (BORGES et al., 2010).

O estoque de produtos acabados está preparado para vendas, vindo do processo produtivo da empresa ou comprados de outros fornecedores, razão pela qual nesses produtos são identificadas elevadas capacidades de investimentos nas organizações comerciais. O objetivo desse processo, é direcionar todos os itens a um padrão de qualidade, o que também requer organização, com o propósito de que os produtos cheguem com qualidade até seu destino (SILVA et al., 2019).

É importante calcular a média de vendas dos materiais acabados ou, os que estão quase acabando, para realizar a reposição de estoque, assim como realizar, antes de tudo, um planejamento de custos que possam refletir nas fichas de pedidos aos fornecedores, para que o capital não seja tão alto e as perdas sejam reduzidas, seguindo o volume das requisições no período correto (POZO, 2015). 


\subsection{TIPOS DE CONTROLE DE ESTOQUE}

Conforme Barbosa (2014), o controle de estoque possui a função de controlar o estoque corretamente, visando colaborar com o gerenciamento e compra dos produtos. Portanto, o controle é um mecanismo gerencial que informa ações ou transformações inadequadas, não autorizadas ou previstas, propiciando até mesmo o cuidado, as orientações institucionais e a análise das diretrizes.

O principal objetivo das empresas é maximizar os resultados, alcançando o percentual máximo de lucro possível, e reduzindo os gastos, o que demanda um controle padronizado e eficiente de estoque. O sistema de controle é formado por um conjunto de intervenções, essas ações aplicadas, além de alcançar a eficiência, contribuem com resultados satisfatórios (BATISTA et al., 2016).

O controle de estoque compreende o processo de elaborar e utilizar informações para tomada de decisões, todos os métodos possuem indicadores de produtividade e, ainda, desenvolvem análise acerca dos instrumentos que baseiam esse serviço. Ele é necessário para organizar seus produtos ou materiais que fisicamente se encontram disponíveis. Objetivando um atendimento com qualidade e alcançando de forma direta, o consumidor final (SOUZA, 2017).

$\mathrm{Na}$ empresa, o sistema de controle atua para medir o tempo dos produtos, controlando tanto o período, quanto, a necessidade dos seus serviços, os quais possuem o mesmo objetivo, propor qualidade. No Polo Industrial, as empresas organizam o seu controle de estoque, segundo as estratégias do gerenciamento de estoque, estes se encontram correlacionados com o processo de compras. E esse procedimento é realizado para assegurar que tudo ocorra corretamente no inventário (NASCIMENTO e SOUZA, 2014).

O controle do estoque é uma função realizada por pessoas que não trabalham nas linhas de produção de forma direta, existe uma equipe de abastecimento que segue todas as linhas, logo, os operários envolvidos no setor de produção, não precisam 
se preocupar com os materiais necessários para seu trabalho. Os procedimentos padronizados contribuem para padronizar a produtividade, desenvolvendo métodos que possam controlar tudo que sai e entra no estoque. Existem diversas técnicas de contabilização dos estoques, onde é possível destacar o PEPS, UEPS e o Preço Médio (SILVA, 2019).

\subsubsection{PEPS}

Para alcançar resultados positivos, o estoque deve seguir o padrão adequado. Desta forma, o PEPS utiliza da técnica da cronologia das entradas e saídas dos materiais, em que os itens mais antigos do estoque devem sair primeiro. Isto é, os materiais que entraram primeiro no estoque, conquistaram logo a saída da organização. Neste método, o custo e preço de venda da mercadoria segue um cálculo conforme o custo do estoque com mais tempo (SANTOS, 2019).

Segundo Rodrigues (2015), é selecionada a ordem temporal de entrada dos produtos no estoque para a sua saída, por esse motivo, as unidades ou lotes seguem a direção prioritária sobre os comercializados, e o valor a ser vendido se baseia no seu preço de compra.

Desta forma, é necessário a monitoração do estoque pela administração, e, mesmo que os materiais do estoque sejam armazenados de forma inadequada, o custo da matéria-prima é valorizado já nas primeiras compras (CARVALHO, 2016).

O controle PEPS é bastante utilizado em empreendimentos, em que os itens vendidos possuem datas de validade, pois permite que os lotes de produtos mais antigos saiam primeiro (BITENCOURT, 2018).

Quadro 1- Exemplo Prático da PEPS

\begin{tabular}{|l|l|l|l|l|l|l|l|l|l|}
\hline & $\begin{array}{l}\text { Entra } \\
\text { da }\end{array}$ & & & $\begin{array}{l}\text { Saíd } \\
\text { a }\end{array}$ & & & $\begin{array}{l}\text { Estoq } \\
\text { ue }\end{array}$ & & \\
\hline Data & Qtd. & V.u & Total & Qtd. & V.u & Total & Qtd. & V.u & Total \\
\hline
\end{tabular}

RC: 100860

Disponível em:

https://www.nucleodoconhecimento.com.br/contabilidade/instrumento-de-adequacao 


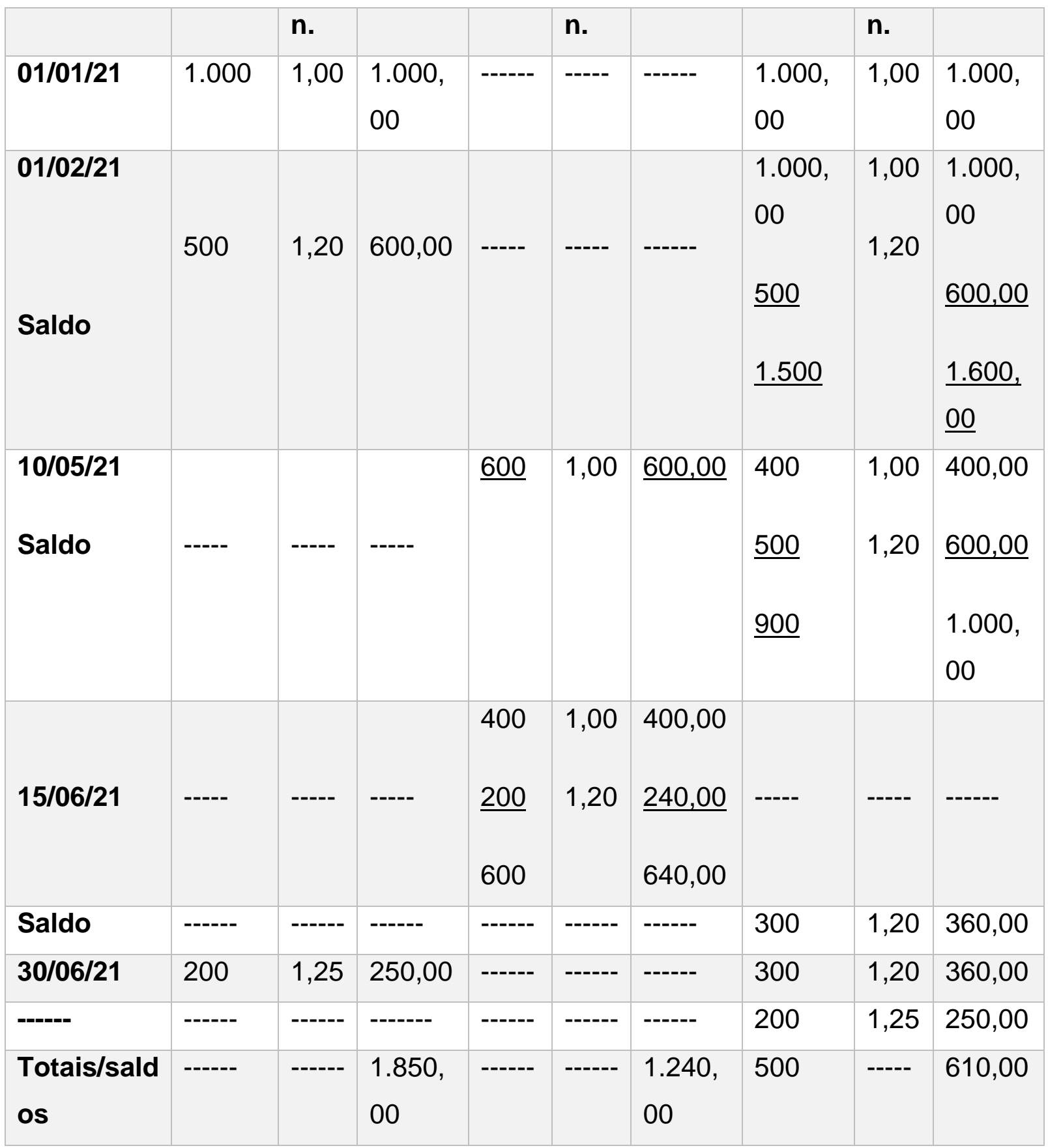

Fonte: Teotônio (2018) 
Nas baixas foi dado abatimento em 600 unidades vendidas a $R \$ 1,00$, totalizando $R \$ 600,00$, de modo a restar 900 unidades que somam $R \$ 1.000,00$. No dia $15 / 06$ foram vendidas 400 unidades, cada uma por $R \$ 1,00$, e 200 componentes, com valor de cada a $R \$ 1,20$, totalizando 600 unidades a $R \$ 640,00$. Em 30/06, foram vendidas 200 componentes a $R \$ 1,25$ cada, totalizando $R \$ 250,00$, e uma quantidade de 200 a $R \$ 1,25$, totalizando $R \$ 250,00$.

\subsubsection{UEPS}

Ao contrário do PEPS, no método UEPS ou LIFO, os últimos produtos que entram são os primeiros a sair. Desta forma, essa técnica calcula o custo do estoque, com base nos últimos itens que chegam ao almoxarifado (SANTOS, 2018). No entanto, quando o cálculo agrega o valor dos primeiros produtos do estoque, ocorre o enquadramento como se fosse dos primeiros materiais vendidos. Sendo assim, o valor total do estoque é extraído por meio do custo do último preço (DAVID et al., 2019).

Comumente esse valor é mais alto, visto que, no final do processo, ocorre um acréscimo positivo de material, onde o UPES abate os seus valores no preço dos produtos em estoque. Existem ainda dificuldades para se aplicar essa técnica quanto a redução do valor tributável, após a realização de cálculo (CARVALHO, 2016).

A legislação fiscal brasileira não aprova que este sistema seja utilizado sem autorização pelas organizações, por se tratar de um método com comparação mais próxima da realidade (RODRIGUES, 2015). Nessa forma de administração, além da elaboração do preço se basear no último lote recebido, a prioridade de venda e saída são dos lotes recebidos recentemente (BITENCOURT, 2018).

Quadro 2- Exemplo Prático da UEPS

\begin{tabular}{|l|l|l|l|l|l|}
\hline Entra & Saíd & Estoq & \\
\hline
\end{tabular}




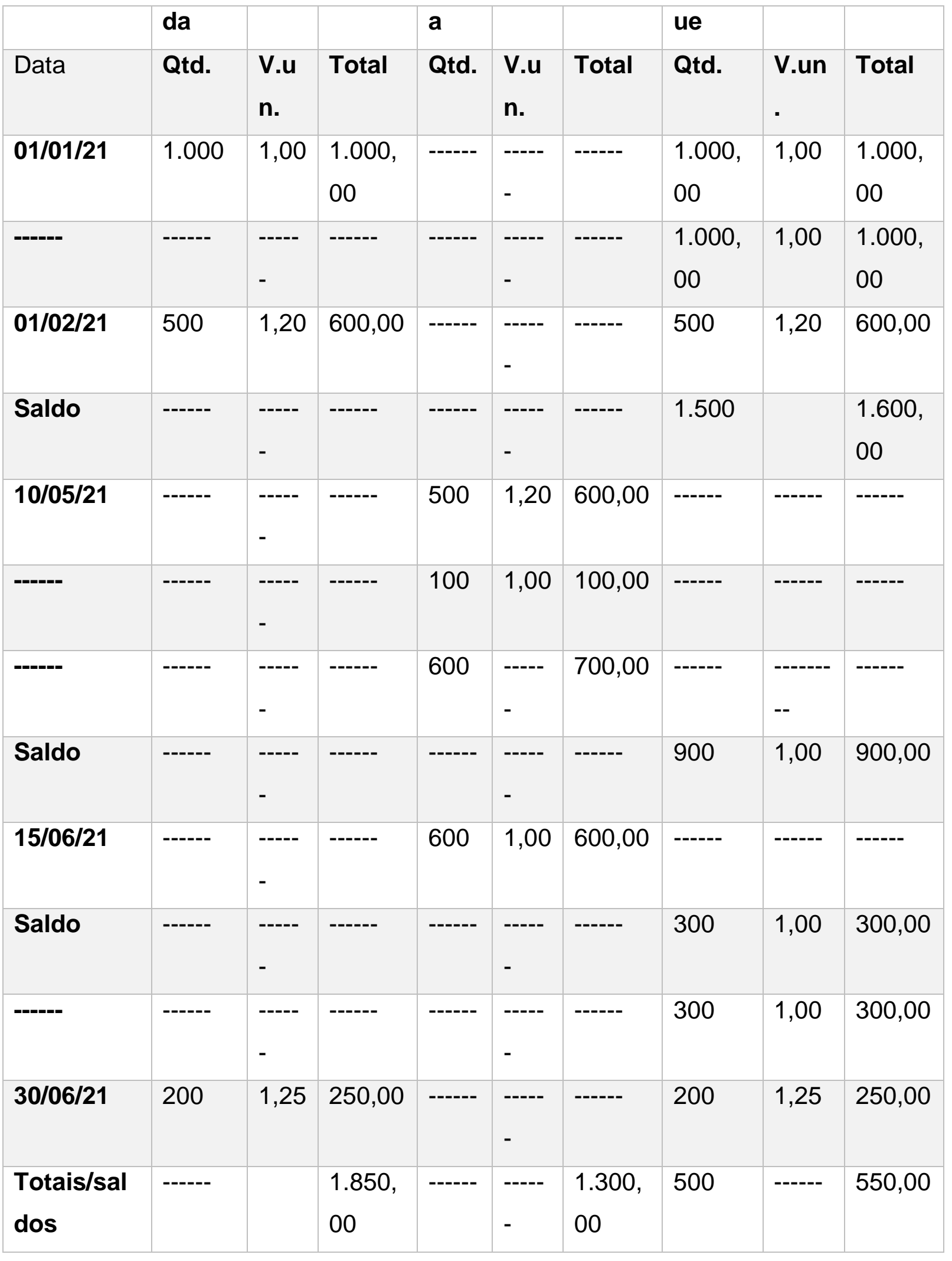

Fonte: Teotônio (2018).

RC: 100860

Disponível em:

https://www.nucleodoconhecimento.com.br/contabilidade/instrumento-de-adequacao 
No dia 01.01, foi comprada 1.000 unidades, com valor de $R \$ 1,00$ a unidade, totalizando $R \$ 1.000,00$. No dia 01/02 foram adquiridas 500 unidades, com custo individual de $R \$ 1,20$, somando $R \$ 600,00$. No dia $10 / 05$ foram vendidas 500 unidades por $R \$ 1,20$, totalizando $R \$ 700,00$. Em 15/06 foram vendidos 600 componentes, dando baixa a $R \$ 1,00$, restando 300 em estoque, totalizando $R \$$ 300,00. No dia 30/06, foram adquiridos 200 componentes a $R \$ 1,25$ a unidade, somando $R \$ 250,00$.

\subsubsection{CUSTO MÉDIO}

É fundamental, antes de analisar os custos, analisar como está o andamento do mercado, assim, o custo médio simboliza o valor da média dos gastos com a compra de cada material. Consiste no valor pago pelo próprio item somados aos acréscimos do frete, impostos, e outras despesas relacionadas aos alcances dos mesmos (DUTRA, 2018). Sendo assim, os custos precisam ser administrados por um profissional competente, que conheça o conceito das premissas da globalização dos mercados, resultando em um contexto de reestruturação e flexibilização dos processos produtivos acerca da realidade e do desenvolvimento econômico (SILVA, 2018).

Segundo Ferreira et al. (2018), para cada entrada de um produto no estoque, o sistema fará o cálculo automático do custo médio, necessitando fazer o controle financeiro das empresas. O objetivo desse método é reduzir os gastos através de planejamento, criação de estratégias e treinamentos, dentre outros (SILVA et al., 2018).

Os custos estão relacionados à prevenção de atualização de lançamento que não esteja conforme o padrão desejado, pois, o sistema normaliza o custo médio para o mesmo assumir o valor digitado, sem desenvolver nenhum cálculo. Todo custo médio é semelhante ao custo total, conhecido como média importante móvel, onde pode ser dividido pela quantidade de bens produzidos (IZIDORO, 2016). 
Quadro 3- Exemplo Prático de Custo Médio

\begin{tabular}{|c|c|c|c|c|c|c|c|c|c|}
\hline & $\begin{array}{l}\text { Entra } \\
\text { da }\end{array}$ & & & $\begin{array}{l}\text { Saíd } \\
\text { a }\end{array}$ & & & $\begin{array}{l}\text { Estoq } \\
\text { ue }\end{array}$ & & \\
\hline Data & Qtd. & $\begin{array}{l}\text { V.u } \\
\text { n. }\end{array}$ & Total & Qtd. & $\begin{array}{l}\text { V.u } \\
\text { n. }\end{array}$ & Total & Qtd. & $\begin{array}{l}\text { V.u } \\
\text { n. }\end{array}$ & Total \\
\hline $01 / 01 / 21$ & 1.000 & 1,00 & $\begin{array}{l}1.000 \\
00\end{array}$ & ----- & ---- & ------ & 1.000 & 1,00 & $\begin{array}{l}1.000 \\
00\end{array}$ \\
\hline $01 / 02 / 21$ & 500 & 1,20 & 600,00 & ----- & ----- & ------ & 1.500 & 1,07 & $\begin{array}{l}1.600 \\
00\end{array}$ \\
\hline $10 / 05 / 21$ & ----- & ----- & ------ & 600 & 1,07 & 642,00 & 900 & 1,07 & 963,00 \\
\hline $15 / 06 / 21$ & ------ & ----- & ------ & 600 & 1,07 & 642,00 & 300 & 1,07 & 321,00 \\
\hline $30 / 06 / 21$ & 200 & 1,25 & 250,00 & ----- & ----- & ------ & 500 & $\begin{array}{l}1,14 \\
2\end{array}$ & 571,00 \\
\hline $\begin{array}{l}\text { Totais/sald } \\
\text { os }\end{array}$ & ----- & ----- & $\begin{array}{l}1.850 \\
00\end{array}$ & ------ & ----- & $\begin{array}{l}1.284, \\
00\end{array}$ & 550 & ----- & 571,00 \\
\hline
\end{tabular}

Fonte: Teotônio (2018)

No dia $01 / 01$ haviam 1.000 unidades a $R \$ 1,00$ cada, totalizando $R \$ 1.000,00$. Em 01/02 haviam 500 unidades, com valor individual de $R \$ 1,20$. A apuração é realizada da seguinte forma, há um total de 1.500 componentes, com o custo médio de $R \$$ $1.600,00$ dividindo por 1.500 unidades, dando baixa no valor unitário de $R \$ 1,07$. No dia 10/05, foram vendidos 600 componentes com valor individual de $R \$ 1,07$, totalizando $R \$ 642,00$. Realizando o custo médio de $R \$ 321,00$ em estoque, dividido por 300 , resultando em $R \$ 1,07$ a unidade. Em 30/06, foi comprada 200 unidades, com valor de $\mathrm{R} \$ 1,25$, totalizando $\mathrm{R} \$ 250,00$. Realizando a apuração do custo médio, de $R \$ 571,00$ em estoque dividido para 500 componentes, resultando no custo médio de $R \$ 1,142$. 


\subsection{GESTÃO DE ESTOQUES}

O gerenciamento de estoques destaca três objetivos importantes: o planejamento, a melhoria do sistema de gestão e o controle. Sendo que o planejamento corresponde à pergunta que decide o cenário do quanto, e quando acrescentar. E o controle está relacionado a monitoração e descrição dos dados reais, e a conferência das formações planejadas, observando os possíveis motivos dos desvios que possam ocorrer durante o processo (SENNE e UCHOA, 2019).

É indispensável o conhecimento das definições e dinâmicas do estoque da empresa pelo administrador, com o objetivo de qualificar os custos e as quantidades dos produtos adicionados sem comprometer a sua divisão efetiva. O pensamento, então, é possuir um estoque satisfatório que atenda com perfeição a produção ou distribuição sem onerar financeiramente o departamento com materiais que, supostamente, podem possuir uma quantidade alta (SILVA e PANNONI, 2020).

O objetivo da Gestão de Estoques pode otimizar as quantidades de produtos no processo, com intuito de diminuir custos de preservar esses materiais em estoque, também de diminuir os custos ligados à ausência no processo. Dentre os custos de preservar em estoque, se pode pontuar o custo de preservar estruturas de armazenagem, de possibilidades devido o capital parado, de manter colaboradores dedicados no controle físico dos materiais, e, bem como, custos menos próprios, como de obsolescência destes (PYKE et al., 2017, p. 533).

Para Rocha (2019), a empresa deve possuir uma gestão ativa e comprometida com os estoques, onde possa seguir a política da empresa e suas normas, buscando ideias inovadoras. Assim, a gestão de estoque organiza tudo que sai e entra, controlando e obedecendo às técnicas relativas, já que, tudo que é distribuído precisa de um planejamento prévio para ter como perpassar qualquer eventualidade no planejamento.

A gestão de estoque, aplicada de forma correta, contribui com a melhor produtividade, qualidade de serviço e produto. Sendo assim, para ocorrer uma melhoria na empresa, é necessário a transformação nas decisões tomadas, 
ocorrendo uma reformulação da disciplina e organização. Atualmente, possuir um sistema de gestão de estoques, permite que a empresa encontre uma posição que seja vantajosa, diante de seus concorrentes (CARVALHO, 2016).

\subsubsection{TÉCNICAS E PROCEDIMENTOS DE INVENTÁRIO}

As técnicas de inventário consistem em propostas de implementação que possibilitam a sua organização, é por esse motivo, que aprender como fazer um inventário de estoque é fundamental para o desenvolvimento de uma empresa. Logo, o inventário é um procedimento que classifica, identifica e contabiliza todas as mercadorias que se encontram no estoque (FOGAÇA, 2020).

Seu procedimento se trata de um trabalho completo e atualizado de estoque, que demanda o uso de técnicas corretas, com objetivo de obter os resultados esperados. Portanto, é importante que o inventário ocorra pelo menos uma vez no ano, para acompanhar o andamento da organização do trabalho da empresa. O inventário é recomendado nas empresas para conferência dos estoques, fazendo uma comparação do físico com o contábil (ROCHA, 2019).

Segundo Coelho (2017), o inventário é escolhido conforme a necessidade da empresa, podendo ser periódico devido à ausência de sistemas tecnológicos de controle de estoques. Esse método permite levantar e quantificar os custos e saldos. Desta forma, através das técnicas do inventário, são identificados problemas existentes em uma organização, sendo fundamental para empresas de pequeno e grande porte.

Nesse contexto, de acordo com Jacintho (2012), tanto o inventário periódico, como o inventário rotativo e tecnológico, correlaciona o saldo físico e o contábil, tendo um custo menor.

Uma das técnicas do inventário, é definir uma data e horário para o início da contagem, verificar quais colaboradores podem estar sendo envolvidos neste processo, considerando que estes devem passar por um treinamento, e escolher a 
ferramenta correta de acordo com a empresa. Assim, os materiais são selecionados por grupos classificados pelo líder do setor (DAMO, 2015).

\subsection{PAPEL DA AUDITORIA NAS ORGANIZAÇÕES}

É necessário compreender o papel da auditoria na empresa, pois seu conceito e aplicação afeta a estrutura da mesma, desde a diretoria até o estoque (LÉLIS e PINHEIRO, 2012).

$\mathrm{Na}$ empresa, a auditoria objetiva analisar e verificar se os setores estão em harmonia através do uso de técnicas e princípios que possibilitam garantir a certificação da empresa, ou seja, se ela está apta a continuar desenvolvendo seus serviços. O desenvolvimento da auditoria no Brasil ocorreu a partir da necessidade de se auditar os investimentos internacionais que foram implantados no país (ATTIE, 2018).

O trabalho de auditoria, está dividido em várias etapas, pelos quais, são apontados procedimentos a serem seguidos, baseados no objetivo que a empresa deseja conquistar. A auditoria interna tem papel fundamental na prestação de contas, medição de desempenho e no sistema de informações da empresa, utilizando normas e padrões técnicos e éticos segundo o interesse do empreendimento (LIMA, 2011).

Ainda sobre a função da auditoria na empresa, destaca-se a análise e detecção de inconsistências internas presentes nos controles internos e contábeis da empresa, como fraudes e erros. Esse processo objetiva auxiliar a alta administração na tomada de decisão empresarial, se preocupando principalmente com os assuntos contábeis, fiscais, financeiros e tributários que envolvem uma empresa (DIAS et al., 2019).

Sendo assim, a auditoria permite o controle do patrimônio e afere se os controles internos correspondem aos objetivos propostos, e se os recursos da empresa estão sendo usados com eficiência e eficácia. A relevância da auditoria se encontra na 
rotina diária das empresas para auxiliar nos planos traçados, resistindo às inúmeras dificuldades apresentadas (SANTOS, 2016).

\subsubsection{AUDITORIA INTERNA}

Crepaldi (2016) aponta que a auditoria interna retrata um controle gerencial em que se aplica o estudo e análise da eficácia de controles específicos, considerando que seu uso é optativo e que seus métodos procedem como mecanismos de auxílio a administração, assim como, a análise da operação dos controles internos.

Ainda que a auditoria interna e externa possua métodos semelhantes, ambas possuem objetivos e destinatários diferenciados. Trata-se, como o próprio nome diz, de um tipo de auditoria que pertence ao ambiente interno da empresa, ao passo que a auditoria externa, no que lhe concerne, não está envolvida na estrutura organizacional da empresa (NASCIMENTO, 2020).

Para Pinheiro (2013), a auditoria interna tem como principal objetivo, garantir que a empresa siga de forma correta as políticas, diretrizes e procedimentos vindos da cúpula diretiva, observando possíveis distorções funcionais nas áreas organizacionais da empresa, motivando, dessa maneira, o cumprimento dos objetivos da organização.

Alves e Sarmento (2011) afirmam que a auditoria possui características do controle, visando realizar o alinhamento. Sendo assim, a auditoria interna faz parte do processo de gestão de riscos e do processo de governança, com a finalidade de diferenciar resultados da auditoria interna, de resultados do controle interno, uma vez que ambos não são a mesma coisa.

Para Ribeiro e Coelho (2013), auditoria consiste em uma técnica contábil que objetiva assegurar a veracidade dos dados vindos dos registros contábeis. Desta forma, a auditoria interna não é somente um mecanismo de detecção de falhas, mas também um meio de prevenção de falhas, deste modo, quando os departamentos 
são fiscalizados, os funcionários da empresa tendem a ser mais cuidadosos no exercício de suas funções.

\subsubsection{PERFIL DO AUDITOR INTERNO}

O auditor interno tem o dever de identificar os pontos fracos da empresa na gestão do negócio, e de verificar as causas, observar as consequências e sugerir transformações que solucionem os problemas encontrados. Quando uma auditoria interna é solicitada por parte da empresa, o próprio funcionário pode se capacitar para atuar nessa função, seguindo os pontos críticos da organização, a fim de criar estratégias para solucionar dificuldades por meio do monitoramento e responsabilidade (NASCIMENTO, 2020).

Para Ribeiro (2013), a auditoria interna deve atuar como instrumento de apoio à gestão, objetivando analisar se o controle interno está em efetivo funcionamento. Com isso, o auditor interno, quando cabível, pode optar com ideias de melhorias nos controles internos ou implementação de controles, já que, este conhece onde estão as dificuldades e como devem ser solucionadas.

O auditor interno deve desenvolver sua função com integral independência profissional, envolvendo todas as condições indispensáveis ao auditor externo, exigindo da empresa, o cumprimento daquelas que lhe cabem. Ele deve realizar sua função com total obediência às políticas de auditoria e com relação de emprego, sem que lhe seja retirada a independência profissional, pois, sua subordinação à administração da empresa precisa ser apenas sob o aspecto funcional (MOREIRA e BARAN, 2018).

De acordo Dias (2019), o auditor interno, nas suas práticas, deve se portar de forma imparcial, auxiliando na análise e resolução de problemas práticos, passando informações fidedignas através de uma abordagem sistêmica e disciplinada com foco na gerência de riscos, controles internos e governança corporativa. Assim, é 
importante ficar ciente de que toda avaliação realizada na empresa, deve ser de pura veracidade e competência.

Portanto, para desenvolver com competência suas responsabilidades profissionais, os auditores precisam de um conjunto de habilidades e competências obtidas através de uma formação técnica e cultural sólida. Também é recomendado manter um bom relacionamento com o auditado, agindo com respeito aos setores submetidos aos exames e se preocupando primeiramente com a produção de seu trabalho (ALMEIDA, 2012).

\subsubsection{PROCEDIMENTOS DE AUDITORIA INTERNA PARA O ESTOQUE}

De acordo com Attie (2018), dentre os procedimentos de auditoria nos estoques, o inventário físico representa o procedimento inicial, que é acompanhado pelo auditor pessoalmente, dando início a verificação de todos os documentos existentes no setor do estoque. Este determina a existência de itens, e se estão seguindo o padrão corretamente.

Desta maneira, a auditoria de estoque começa com a análise de documentos em que ocorre as verificações de dados para confirmar a existência do controle de patrimônio da instituição auditada. $\mathrm{O}$ auditor, aplica primeiro um questionário de controle interno, para observar a existência desse controle na organização, e as respostas deste questionário são analisadas para a elaboração de procedimentos estratégicos dentro da empresa (GIACOMELLI, 2014).

Segundo Crepaldi e Crepaldi (2016), a observação do estoque é um procedimento aceito pelas normas de auditoria, que podem colaborar para que os auditores consigam atingir determinados objetivos, de modo que concerne a propriedade, quantidades, existência verdadeira e possibilidade de venda. Realizar uma auditoria de estoque, é fundamental para organização da empresa, se esta deseja seguir o padrão exigido pelas normas da auditoria. 
A primeira função desenvolvida na auditoria pelo auditor, é a inspeção dos materiais, seguido da análise dos registros do estoque e dos documentos fiscais. Quando uma empresa é de grande porte, os métodos seguem os mesmos da empresa de pequeno porte, porém, é preciso que tenha mais de um auditor para organizar a contabilização do estoque, por se tratar de uma avaliação periódica de qualquer atividade da organização (GRANATO, 2012).

Devido ao fluxo contínuo do estoque, organizar o patrimônio e reunir todos os documentos de entrada ou saída de produtos e ativos, não é uma tarefa fácil para o gestor. Realizar este tipo de auditoria de estoque é uma excelente oportunidade para desenvolver um controle de qualidade do estoque, verificando minuciosamente se os processos contábeis da empresa estão funcionando da forma correta (JÚNIOR, 2020).

\subsubsection{RESULTADOS DA AUDITORIA INTERNA}

Os resultados da auditoria interna, se apresentam como aspectos obtidos durante o processo auditado, sua previsão tende a auxiliar a empresa a identificar suspeitas de algo que não está no padrão desejado. Após a obtenção das evidências da auditoria interna, é importante tomar algumas providências para a prevenção de um relatório de parecer não desejado (CFC, 2012).

Segundo Lins (2012), esses resultados são tratados para identificar ocorrências de desvios e apontar erros, desperdícios, trabalho repetitivo, dentre outros. Por isso, quando uma auditoria é finalizada, o relatório final deve estar claro, apresentando os resultados dos seus trabalhos realizados.

Todo diagnóstico final deve mostrar, em documento, a comprovação de certas inconformidades existentes no estoque de uma empresa, isso mostra que tudo que foi realizado teve retorno. Os procedimentos de observância são necessários para promover melhor segurança na organização e compreender melhor se os controles internos estão funcionando como o esperado (SIMÕES, 2020). 
O resultado da auditoria é um relatório de toda profundidade dos trabalhos, pelo qual a empresa pode criar um plano de ação para sustentar o ambiente que se encontra fragilizado. É necessária uma auditoria mais detalhada para desenvolver melhor os programas de trabalho no período editado, sendo revisado quando necessário (SANTOS et al., 2014).

Uma saída para solucionar os problemas comprovados no decorrer da realização da auditoria, seria a implementação de controles e procedimentos pela empresa auditada. Um relatório final de uma auditoria bem realizado, envolve principalmente, os empresários, fornecedores, financiadores, dentre outros. Caso, durante o trabalho da auditoria forem detectados erros, todos devem ser colocados no relatório final, para contribuir com as melhorias futuras (PINHEIRO, 2013).

\section{MATERIAIS E MÉTODOS}

Os materiais e métodos tem como finalidade apresentar minuciosamente as etapas a serem utilizadas na metodologia, de tal maneira que sejam reproduzidas pelo pesquisador. Consistem em métodos operacionais específicos que se fundamentam em um conjunto de fases desenvolvidas a partir de processos bem definidos. Geralmente, os métodos de pesquisa aplicados para a coleta de dados envolvem a técnica de construção e avaliação, observação, aplicação de questionários e entrevistas, entre outras (PRAÇA, 2015).

\subsection{PROCEDIMENTOS METODOLÓGICOS}

Como método de pesquisa, foi realizada a investigação-ação. A investigação foi realizada a partir de pesquisas secundárias em fontes bibliográficas, baseada em materiais produzidos, como: livros, páginas da internet, publicações periódicas e artigos científicos que se encontram nas bases de dados SciELO, LILACS e Google Acadêmico. E a ação trata-se de um estudo de caso em uma indústria do polo industrial de Manaus. Sendo assim, é fundamental essa etapa de compreender o objetivo de estudo, para propor melhorias a serem implementadas. 
A pesquisa bibliográfica é a etapa inicial para a elaboração concreta de um protocolo de análise, significa que depois da seleção do assunto é fundamental realizar uma revisão bibliográfica da temática proposta. Esse estudo contribui na busca de uma forma apropriada e autêntica de pesquisa e compreensão das variáveis (CAVALCANTE, 2017). O Estudo de Caso objetiva aprofundar fatos e explorar ideias relacionadas a apenas uma unidade ou indivíduo. É a categoria de pesquisa, em que o método se direciona para um caso específico, visando compreender os fatores de forma completa e abrangente (MENEZES et al., 2019).

\subsubsection{QUANTO À NATUREZA}

Esse estudo utilizou o método de abordagem indutiva, baseado na experiência, considerando os princípios predeterminados. Em relação à natureza, a pesquisa é do tipo aplicada. Ela visa produzir aprendizagens para utilização prática relacionadas às respostas de questões específicas (MENEZES et al., 2019).

A pesquisa aplicada atua em conjunto com a pesquisa básica e integra um ciclo de modificação, pelo qual, o entendimento deriva em procedimentos práticos, podendo ser novos processos, objetos ou inovações nas diversas áreas da pesquisa. Ela busca sempre o alcance de resultados completos, sendo assim, ela relaciona-se com objetivos específicos para promover aos problemas, soluções hábeis e aplicáveis (ZUCATTO et al., 2020).

A pesquisa aplicada visa produzir conhecimentos para introdução de práticas relacionadas à solução de problemas específicos. Assim, quando aplicada sobre uma situação, através de conhecimentos desenvolvidos com o objetivo de solucionar os problemas existentes, tem-se um objetivo prático. É onde o autor tem como finalidade realizar uma pesquisa científica direcionada à resolução de problemas intrínsecos. Sendo assim, ela é importante para produzir um novo conhecimento, elevando o que já existe, mas, pô-lo, na prática, atuando na realidade. 


\subsubsection{QUANTO AOS FINS}

Do ponto de vista de seus objetivos, este estudo classifica-se como uma pesquisa descritiva, utilizada para alcançar informações relevantes sobre a temática. A pesquisa descritiva envolve uma pesquisa observacional, em que correlaciona duas categorias semelhantes, deste modo, o método descritivo objetiva o registro, reconhecimento e estudo dos fatores, peculiaridades e variáveis que envolvem o processo (NUNES et al., 2016).

Segundo Andrade (2017), os fatos são apreciados, analisados, relacionados, categorizados e interpretados, sem ocorrer interferência do pesquisador. Isso quer dizer, que os eventos do mundo humano e físico são pesquisados, porém, sem manipulação do investigador.

Pode-se destacar que a pesquisa descritiva visa apresentar características de específicos fenômenos ou grupos, elevando crenças e opiniões de uma específica população. Relaciona-se a essa pesquisa, dado que busca apresentar as características da indústria do distrito industrial, principalmente da área do estoque, apresentando as suas características físicas e profissionais relacionadas ao controle de estoque e auditoria interna.

\subsubsection{QUANTO AOS MEIOS}

Quanto aos meios, esta pesquisa se classifica numa abordagem qualitativa, porque interpreta fenômenos, sendo atribuídos alguns significados que não precisam da utilização de métodos estatísticos, em que o pesquisador somente utiliza o ambiente natural para realização da coleta de dados (MARCONI e LAKATOS, 2017).

Este estudo é de natureza qualitativa, dado que se reuniram informações e foram feitos registros e análise dos dados referentes ao comportamento dos participantes da pesquisa. A pesquisa qualitativa trabalha com o universo de significados, 
motivos, aspirações, crenças, valores e atitudes, correspondendo de forma profunda às relações dos processos e dos fenômenos (MINAYO, 2014).

Afirma-se que a pesquisa de abordagem qualitativa tem na fonte de pesquisa, um objetivo de fato real, deste modo, o pesquisador utiliza mecanismos como coleta de dados, que pode ocorrer através da observação e análise documental. Os documentos são significativas fontes de informações quando seu conteúdo serve para apreciação de um estudo científico. Para se responder uma pergunta de pesquisa, é recomendado que o pesquisador se aprofunde no entendimento sobre a problemática a fim de servir como orientação para a elaboração de hipóteses que contribuam com uma outra fonte de pesquisa (COSTA et al., 2017).

Posto isso, a coleta de dados ocorreu através de observações diretas e investigações de manuais e documentos internos para a obtenção de informações. Com relação aos dados coletados, evidenciou-se na pesquisa as seguintes etapas: reunião de dados de documentações, registros do objetivo do estudo e observação em campo.

\section{APRESENTAÇÃO E ANÁLISE DE RESULTADOS}

Esta seção apresenta os resultados da pesquisa de estudo de caso. Portanto, serão apresentados os dados da empresa em estudo, em seguida as análises de dados e por fim o resultado e as recomendações.

\subsection{CARACTERIZAÇÃO DA EMPRESA}

A coleta de dados foi desenvolvida em uma indústria eletroeletrônica localizada no polo industrial de Manaus, que não permitiu divulgar o nome na produção científica. Essa empresa foi inaugurada no Brasil, em 2011, com a finalidade de elevar seus investimentos por meio da instalação de seu apoio de produção no polo industrial de Manaus, começando pela produção de produtos direcionados à placas-mãe e decodificadores para televisores. 
A empresa é de porte nominal grande, possui faturamento presumido de $R \$$ 300.000.001 a 700.000.000 por ano, e tem, em média, de 501 a 1000 funcionários.

Figura 01- Organograma da Indústria

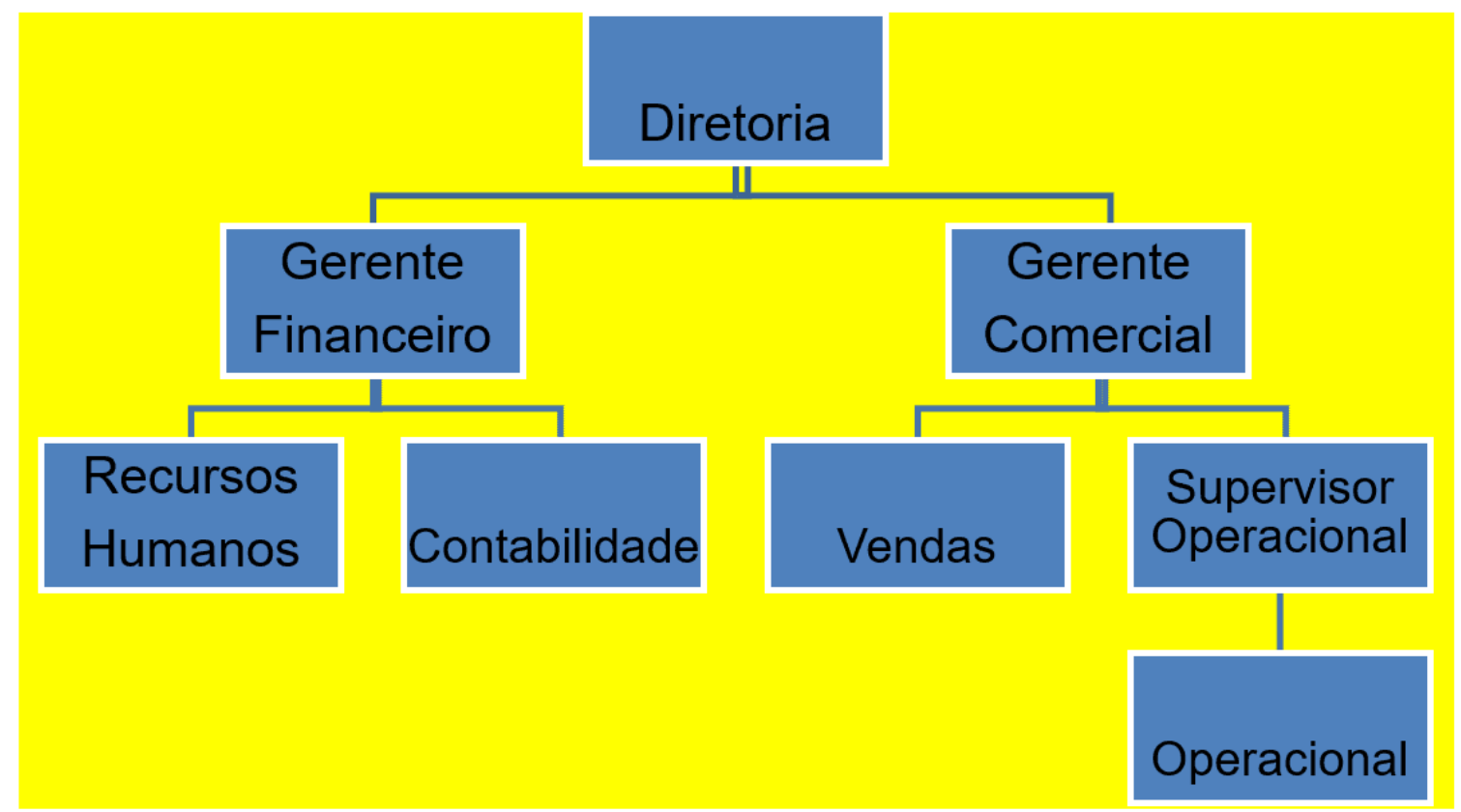

Fonte: Resultados da Pesquisa (2021).

\subsection{COLETA E ANÁLISE DE DADOS}

A indústria pesquisada neste estudo foi fundada em dezembro de 1917, é a terceira maior empresa de fabricação de televisores do mundo, e a segunda do Japão. Além de cabos, são fabricados também conectores, terminais, módulos eletrônicos e outros componentes que contribuem para que os televisores funcionem corretamente.

A organização declina com a falta de componentes para a produção de televisores, e quando se produzia elevada quantidade, gerava o acúmulo de produtos no estoque, reduzindo assim, o espaço físico. Entre os problemas que comprometiam sua produção, podem ser elencados: estoque desorganizado; falta de controle na chegada de materiais; aumento da área sem planejamento; e demora na separação 
dos pedidos. A indústria sofria com a falta de produtos e com a superprodução de alguns, posto que, não existia um gerenciamento na produção, gerando o denominado, gargalo de fábrica. Isso também resultava na falta de matéria-prima, outras vezes, permanecia lotado apenas com um tipo de componente.

Assim sendo, o objetivo da temática foi atingido, analisando as falhas constatadas na organização. Dessa forma, foi identificado a necessidade da realização da auditoria interna, por ser uma forma indispensável à gestão, para realizar uma assistência do controle interno que possibilite a eficácia na administração. Ela não pode ser observada como uma ação punitiva, mas, uma forma para reconhecer falhas e alcançar resultados, para posteriormente, implantar um sistema automatizado que gerencie todas as informações do setor de almoxarifado.

\subsection{RESULTADO E RECOMENDAÇÕES}

Foi possível sugerir como estratégia de melhoria, a implantação do sistema de gestão de estoque $A B C$, já que a indústria não possuía nenhum sistema implantado. Com essa nova introdução, ocorrerão inúmeros benefícios, como, por exemplo, a redução do desperdício, diminuição dos custos operacionais, entre outros fatores. É importante direcionar as atenções para as rotinas em prática, independentemente do método empregado, com a finalidade de não gerar problemas à gestão.

A indústria, ao possuir uma gestão de controle de estoque, apresentará soluções para a falta de peças na produção de tvs. Ao utilizar esse método, fará o registro no controle do estoque periodicamente, conforme a quantidade de componentes disponíveis, confirmando se o saldo apurado no controle de estoque corresponde ao estoque físico existente na empresa.

O modelo a ser aplicado pela indústria pesquisada, é o sistema $A B C$, que considera o nível de importância do produto para a produção, classificando-se em $\mathrm{A}$, os componentes de máxima importância, que representam em média 20\% do investimento realizado no estoque, em $B$, os componentes que representarem em 
média cerca de $30 \%$, e em C, os componentes que representarem os $50 \%$ restantes.

Sendo assim, primeiramente, é essencial que o gestor de estoque compreenda todo o processo de linha de produção, sobre quais materiais são utilizados na produção e quais peças necessitam ser reabastecidas. Conhecendo as matérias primas, os suprimentos e o armazenamento do estoque, o gestor realizará um planejamento, mantendo um sistema controlado com as quantidades estocadas.

Em seguida, será desenvolvido o planejamento estratégico de gestão de estoque, que visa a melhoria dos serviços de atendimento ao consumidor, através do controle do estoque, com monitoramento, fiscalização e gerenciamento das entradas e saídas dos produtos, determinando o que permanece, a quantidade dos produtos e quando devem ser reabastecidos. Isso somente ocorrerá, quando existirem parcerias de fornecedores que forneçam componentes com qualidade, quantidade, tempo de entrega e preço justo.

Por último, será determinado quais materiais ficaram no estoque, controlando o número de itens e definindo os componentes (conectores, circuitos integrados, terminais, tubos, fusíveis e diodos), a forma de abastecimento na linha de produção, a especificação dos códigos, os valores e as cores dos componentes eletrônicos. No quadro 4 é apresentado o comparativo entre as situações antes e depois da implantação do controle do estoque.

Quadro 4 - Comparativo entre as situações antes e após a implantação do controle do estoque.

\begin{tabular}{|l|l|l|l|}
\hline Quesito & $\begin{array}{l}\text { Situação } \\
\text { Antes }\end{array}$ & $\begin{array}{l}\text { Situação } \\
\text { Depois }\end{array}$ & $\begin{array}{l}\text { Resultado } \\
\text { Encontrado }\end{array}$ \\
\hline $\begin{array}{l}\text { Número de colaboradores na } \\
\text { linha de produção }\end{array}$ & & & Ganho de 30\% \\
\hline
\end{tabular}




\begin{tabular}{|c|c|c|c|}
\hline & 30 & 20 & \\
\hline Setor de ocupação & $3232 \mathrm{~m}^{2}$ & $157 \mathrm{~m}^{2}$ & Ganho de $30 \%$ \\
\hline $\begin{array}{l}\text { Produtividade peças } \\
\text { homem/dia }\end{array}$ & 65 & 85 & Ganho de $49 \%$ \\
\hline
\end{tabular}

Fonte: Resultados da Pesquisa (2021).

Observa-se no quadro 4, que os benefícios são inúmeros a partir da aplicação da auditoria e do controle de estoque, pois, ocorrerá redução de números de colaboradores na linha de produção e os ganhos chegarão a $30 \%$. O setor de ocupação no estoque também reduzirá, de $3232 \mathrm{~m}^{2}$ para $157 \mathrm{~m}^{2}$, com ganho equivalente de $30 \%$, e a produtividade de peças por dia passará de 65 para 85 por colaborador, com ganho de $49 \%$.

As propostas de melhorias foram sugeridas para a empresa, mas ainda estão sendo avaliadas pelos gestores.

\section{CONSIDERAÇÕES FINAIS}

As empresas que almejam acompanhar o mercado competitivo, devem se adequar a partir da realização do controle de estoque. Este possibilita que o gestor analise se 0 estoque está sendo utilizado, manuseado e controlado da forma adequada para maximização dos efeitos de feedback do produto. Sem estoque é impossível uma empresa trabalhar, pois este é fundamental para a produção e venda final do produto.

Deste modo, este estudo objetivou analisar a adequação do controle de estoque em uma indústria do polo industrial da cidade de Manaus-AM a partir da realização da auditoria interna. Sendo constatado que, na empresa, atualmente, a contagem da matéria-prima e do produto acabado é realizada de forma manual, devido à falta de um controle interno apropriado que promova qualidade às atividades da organização na área de estoque.

RC: 100860

Disponível em:

https://www.nucleodoconhecimento.com.br/contabilidade/instrumento-de-adequacao 
Quanto ao primeiro objetivo específico: descrever o controle interno a ser utilizado no estoque pela organização, foi comprovado que a auditoria interna se apresenta como uma importante estratégia de melhoria de processos, além de estruturar todas as informações fundamentais de documentação fiscal. Desta forma, os resultados do objetivo específico: comparar o sistema de estoque atual com o que pode ser aplicado, também foi atingido.

Para o campo profissional, este estudo tornou-se essencial, pois, produziu informações sucintas e dados contábeis precisos, que podem auxiliar os contadores nas tomadas de decisões das organizações. Desta forma, esta pesquisa apresentou um diferencial competitivo para as organizações, já que, o estoque e um setor ativo são fundamentais para a sobrevivência das empresas.

Constatou-se, portanto, a importância da auditoria interna no processo de decisão das empresas. Frente ao crescimento das indústrias, verificou-se também a necessidade de se comparar as diferenças que podem se manifestar entre a contagem informatizada e a contagem física do estoque, a fim de se evitar prejuízos. Deste modo, considera-se essencial a participação do auditor na elaboração e fornecimento de demonstrações contábeis, para confirmação das informações fornecidas pela organização.

Através deste estudo de caso, pode-se constatar que a empresa possui falhas nos controles internos no setor de almoxarifado, para o qual foi desenvolvida a proposta de melhoria, a partir da realização da auditoria interna e da implantação de gestão do sistema $A B C$ no estoque. Assim, entre os principais benefícios alcançados, estão a redução dos custos operacionais, diminuição dos desperdícios, melhoria no atendimento aos clientes e, consequente aumento das vendas dos televisores. Sendo que as propostas de melhorias sugeridas à empresa, ainda estão sendo avaliadas pelos gestores.

Esperamos que essa pesquisa possa servir de estudo para outros interessados no assunto abordado e que as sugestões possam ser aceitas pela empresa 
pesquisada, pois as recomendações podem trazer grandes benefícios operacionais e financeiros.

\section{REFERÊNCIAS}

ALMEIDA, M. C. Auditoria: um curso moderno e completo. 8. ed. São Paulo, Atlas, 2012.

ALMEIDA, M. C. Auditoria: um curso moderno completo. 7. ed. São Paulo: Atlas, 2010.

ALVES, J. S. SARMENTO, M. Auditoria Interna: objetivos, organização e funcionamento. p. 103-129. Universidade Lusíada de Lisboa Lusíada. Economia \& Empresa, n. 12. Lisboa, 2011.

ANDRADE, M. M. de. Introdução à Metodologia do Trabalho Científico. 10. ed. São Paulo: Atlas, 2017.

ARALDI, C. E. A importância da auditoria para a tomada de decisão. Lages, 2019.

ARAÚJO, J. U. et al. Gestão de processos industriais: a importância do controle de processo produtivo para a garantia da qualidade final do produto. PUC Goiás, 2020.

Disponível

em:

https://repositorio.pucgoias.edu.br/jspui/bitstream/123456789/1234/1/TCC\%20JURA NDI\%20VERS\%C3\%830\%20FINAL.pdf. Acesso em: 17 ago 2021.

ATTIE, W. Auditoria: conceitos e aplicações. 7.ed. São Paulo: Atlas, 2018.

BARBOSA, W. da S. Redução de custos e seu impacto na gestão de estoque. Instituto Municipal de Ensino Superior de Assis - IMESA, Fundação Educacional do Município de Assis - FEMA, 2014. 
BATISTA, A. P. et al. Implantação de uma ferramenta para o planejamento e controle da produção (PCP) em uma empresa de tintas do polo industrial de Manaus. Revista científica semana acadêmica. Fortaleza, 2016.

BITENCOURT, C. PEPS, UEPS e Custo médio - 0 que é e como funciona. Sobreadministração, 2018.

BORGES C. T. et al. Implantação de um sistema para o controle de estoques em uma gráfica/editora de uma universidade. Revista Eletrônica Produção \& Engenharia, v. 3, n.1, p.236-24, 2010.

COLUSSI, J.; HANGAI, L. A. Indústria 4.0: empresas investem em fábricas inteligentes. 2015.

CAMPAGNARO, G. Gestão de estoque: estudo de caso em uma empresa no ramo de comércio varejista. Fraiburgo, p. 1-72, 2019.

CARVALHO, I. M. F. Análise da Gestão de Estoques em uma Empresa de Pequeno Porte: Rei dos Frios e Conveniências Planaltina. Planaltina/ DF, 2016.

CAVALCANTE, L. E. Da Leitura do Mundo à Leitura da Palavra: A Informação da Mediação da Informação Social à Luz da Teoria de Paulo Freire. In: XVII Encontro Nacional de Pesquisa em Ciência da Informação, 2017. Disponível em: http://enancib.marilia.unesp.br/index.php/index/index. Acesso em: 22 ago. 2021.

CFC. Conselho Federal de Contabilidade. Normas brasileiras de contabilidade: auditoria interna: NBC TI 01 e NBC PI 01. Brasília: CFC, 2012.

COELHO, J. M. Estoques- Métodos de Valoração. 2017.

COSTA, I. S. A. et al. Funções e aplicação das atividades do Planejamento e Controle da Produção em uma indústria de insumos para empresas do setor têxtil do Ceará. Revista gestão em análise, Fortaleza, v. 9, n. 2, p. 159-168, 2020. 
COSTA, M.; STEFANO, F. A era das fábricas inteligentes está chegando. Revista exame, 2014.

COSTA, W. F. et al. Uso de Instrumentos de Coleta de Dados em Pesquisa Qualitativa: Um Estudo em Produções Científicas de Turismo. Revista Turismo Visão e Ação, Vol. 20 - n. 1, 2017.

CREPALDI, S. A.; CREPALDI, G. S. Auditoria contábil: teoria e prática. 10. ed. São Paulo: Atlas, 2016.

DAMO, N. M. Análise das sistemáticas de estoque de bobinas de aço em uma empresa metal-mecânica de grande porte. Panambi, 2015.

DAVID, A. C. R. et al. Estoques: Apuração de custos de aquisição e venda. Revista científica, v.1, n.1, 2019.

DIAS, F. Aprenda os itens necessários para você construir um Referencial Teórico de TCC. Voitto, 2020. Disponível em: https://www.voitto.com.br/blog/artigo/referencial-teorico-tcc. Acesso em: 30 ago. 2021.

DIAS, G. B. et al. A Importância da Auditoria Interna no Processo de Adequação das Informações Contábeis. Revista Ágora. UnimesVirtua, v.3. n.6, 2020.

DUTRA, O. T. Contabilidade de custos: livro didático. 5. ed. rev. e atual. Palhoça: UnisulVirtual, 2018.

FERREIRA, A. O. et al. A gestão de custo como ferramenta para formação de preço: estudo de caso em uma empresa familiar na cidade de Porto Velho. Fundação Universidade Federal de Rondônia. Porto Velho, 2018.

FOGAÇA, G. T. Proposta de implementação de inventário rotativo em uma empresa do segmento de baldes industriais. Universidade Estadual de Campinas- UNICAMP, 2020.

RC: 100860

Disponível em:

https://www.nucleodoconhecimento.com.br/contabilidade/instrumento-de-adequacao 
GASNIER, D. G. Gestão de estoques e suprimentos na cadeia de abastecimento. 2. ed. São Paulo: Imam, 2018.

GIACOMELLI, A. Auditoria interna de estoques: estudo de caso na empresa Aga Cosméticos. Universidade de Passo Fundo, Passo Fundo, RS, 2014.

GRANATO, G. Inventários cíclicos como ferramenta no aumento da acuracidade de estoque. Universidade Federal do Paraná, p. 35, 2012.

HERMES, M. D. N. Tecnologia da informação como ferramenta para logística. Monografias Brasil Escola, 2020.

IZIDORO, C. Contabilidade de Custos. São Paulo: Pearson Prentice, Hall, 2016.

JACINTHO, J. C. A. Sistema de Inventário Rotativo. Revista MundoLogística. São Paulo, n.2, p.14-22, 2008. 2012.

JÚNIOR, V. C. C. Auditoria de estoque: instrumento de controle e gestão adotado por uma loja departamento. Revista Científica Semana Acadêmica, 2020.

LÉLIS, D. L. M.; PINHEIRO, L. E. T. Percepção de Auditores e Auditados sobre as Práticas de Auditoria. São Paulo: R. Cont. Fin. - Usp, 2012.

LIMA, A. C. R. Auditoria Contábil Interna como Instrumento de Apoio para Gestão de Empresas. Novo Hamburgo: Universidade Feevale, p. 21, 2011.

LIMA, A. S. F. Gestão de estoque: diagnóstico empresarial aplicado em uma microempresa de móveis na cidade de Guarapari-ES. Instituto Federal de Educação, Ciência e Tecnologia do Espírito Santo - Guarapari, 2021. Disponível em: https://repositorio.ifes.edu.br/bitstream/handle/123456789/895/TCC\%20Sara\%20FIN AL\%20OK\%2003\%20222.pdf?sequence=1\&isAllowed=y. Acesso em: 17 ago 2021 .

LIMA, F. K. P. de. Auditoria Interna de Estoque como Ferramenta na Prevenção de Fraudes e Desvios de Matéria-Prima. Revista Científica Semana Acadêmica, 
Fortaleza, CE. Edição 208, v.9. ano, 2021. Disponível em:https://semanaacademica.com.br/system/files/artigos/artigo_francine_lima_0.pdf. Acesso em: 10 set. 2021.

LINS, L. S. Auditoria: uma abordagem prática com ênfase na auditoria externa. 2 ed. São Paulo: Atlas, 2012.

MAFFEI, J. L. Curso de Auditoria. São Paulo: Saraiva, 2015.

MANGONI, A. Gestão de Estoques em Supermercados: 0 caso mercado Roso. Passo Fundo, 2014.

MARCONI, M. A.; LAKATOS, E. M. Fundamentos de metodologia científica. 8. ed. São Paulo: Atlas, 2017.

MARQUES, W. L. Contabilidade Geral. Cianorte: Vera Cruz, 2010.

MARTELLI, L. L. Planejamento e controle de estoque nas organizações. Universidade Tecnológica Federal do Paraná, Ponta Grossa. v. 11, n. 02: p. 170185, 2015.

MARTINS, C. A. K.; CONCEIÇÃO, J. F. Gestão de estoques: análise no estoque de uma microempresa de aquecedores. Florianópolis, 2019.

MELO, M. M. de; SANTOS, I. R. dos. Auditoria contábil. 2. ed. Rio de Janeiro. Freitas Bastos, 2017.

MENEZES, A. E. N. Metodologia Científica: teoria e aplicação na educação a distância. Petrolina, 2019.

MINAYO, M. C. de S. (Org.). O desafio do conhecimento: pesquisa qualitativa em saúde. 14a ed. Rio de Janeiro: Hucitec, 2014. 408 p. 
MOREIRA, A. de L.; BARAN, K. P. A Importância da Auditoria Interna para as Organizações. Revista Científica Multidisciplinar Núcleo do Conhecimento, ano 03, Ed. 02, Vol. 05, pp. 84-98, Fevereiro de 2018.

NASCIMENTO, P. F.; SOUZA, L. L. F. Classificação da Pesquisa: Natureza, método ou abordagem metodológica, objetivos e procedimentos Francisco. In: Metodologia da Pesquisa Científica: teoria e prática - como elaborar TCC. 1. ed. Brasília: Thesaurus, 2014.

NASCIMENTO, S. S. Auditoria interna e sua dinâmica no contexto organizacional. Campo Grande, 2020.

NUNES, G. C. et al. Pesquisa científica: conceitos básicos. Id on Line Multidisciplinary and Psychology Journal, ano 10, n. 29, 2016.

PACHECO, D. A. J. Teoria das restrições, Lean manufacturing seis sigma: limites e possibilidades de integração. Production, v.24, n.4, p.940-956, 2014.

PEPINELLI, R. de C. C. et al. A Percepção dos Auditados em Relação às Competências Comportamentais dos Auditores Independentes: Um estudo empírico na região da grande Florianópolis/SC. São Paulo: 11ํㅡㄹ Congresso Usp de Controladoria e Contabilidade, 2011. 18 p.

PINHEIRO, C. G. A. Acrescentar valor à organização com a auditoria interna. Porto: ISCAP, 2013.

PINHEIRO, C. G. A. Acrescentar valor à organização com a Auditoria Interna. Instituto Superior de Contabilidade e Administração - Porto Seguro, 2013.

PIRES, S. R. Gestão da cadeia de suprimentos: conceitos, estratégias, práticas e casos. São Paulo: Atlas, 2016. Disponível em: https://repositorio.ufpb.br/jspui/bitstream/123456789/15510/1/KKFR23072019.pdf. Acesso em: 17 ago. 2021. 
PORTAL EDUCAÇÃO. Tipo de Estoque. 2013. Disponível em: https://siteantigo.portaleducacao.com.br/conteudo/artigos/educacao/tipos-deestoque/40254. Acesso em: 16 set.2021.

POZO, H. Administração de Recursos Materiais e Patrimoniais: Uma Abordagem Logística. São Paulo: Atlas, 2010.

POZO, H. Logística e gerenciamento da cadeia de suprimentos. São Paulo: Atlas, 2015.

PRAÇA, F. S. G. Metodologia da Pesquisa Científica: Organização Estrutural e os Desafios para Redigir o Trabalho de Conclusão. Revista Eletrônica Diálogos Acadêmicos, 08, № 1, p. 72-87, 2015.

PUCHKOVA, A. et al. Balancing Pull and Push Strategies within the Production System. International Federation of Automatic Control., v.49-2, p.66-71, 2016.

PYKE, D. et al. Inventory and Production Management in Supply Chains. New York, USA: CRC Press. p. 533, 2017.

RIBEIRO, O. M.; COELHO, J. M. R. Auditoria fácil. 2.ed. São Paulo: Saraiva, p.384, 2013.

ROCHA, K. K. F. Análise de estoque de produtos acabados em uma indústria automobilística: procedimento para a melhoria e controle da acuracidade. João Pessoa- PB, 2019.

ROCHA, T. M. C. Gestão de estoque: estudo de caso na empresa de transporte rodoviário: Rio Ita Ltda. Niterói, 2019.

RODRIGUES, G. L. Avaliação do método de mensuração dos estoques em uma empresa S.A um estudo de caso. 2015. Disponível em: https://www.aedb.br/seget/arquivos/artigos15/512243.pdf. Acesso em: 19 ago. 2021. 
RUSSO, C. P. Armazenagem, Controle e Distribuição. Curitiba: InterSaberes, 2013.

SANTOS, E. S. et al. A importância da auditoria contábil nas empresas e entidades do terceiro setor. Revista Eletrônica Fanese, v.3, n.1, 2014.

SANTOS, R. M. Gestão de estoque para alimentos perecíveis: um estudo de modelos aplicáveis e levantamento das variáveis para parametrização. Simpósio de Engenharia de Produção, 2019.

SANTOS, S. Q. Auditoria interna de gestão: seus reflexos e suas contribuições no processo decisório de uma concessionária de motocicletas, situada na cidade de Barreiras - Bahia. Revista Científica Semana Acadêmica, 2016.

SENNE, C. A.; UCHOA, L. G. Modelos de reposição de estoque: estudo de caso em uma empresa de pequeno porte. Universidade Federal do Espírito Santo, Vitória, p. 1-75, 2019.

SILVA, D. A. Redução dos Custos de Qualidade em uma Empresa do PIM. Faculdades IDAAM, Manaus, 2018.

SILVA, K. M.; VOLANTE, C. R. A importância do sistema Kanban para o gerenciamento e controle de estoque de uma empresa. Revista Interface tecnológica, 2019.

SILVA, M. C. N. et al. Gestão de estoque: implementação da ferramenta 5W2H para o controle de estoque das matérias-primas. 2019.

SILVA, M. L. V.; LOOS, M, J. A importância da utilização de indicadores de desempenho de gestão de estoques na logística de suprimentos de uma indústria calçadista. Revista FFBusiness, Fortaleza, v.14, № 17, jan. 2016. 
SILVA, R. C. Gestão estratégico de custos: Target costing aplicado à atividade agropecuária- um estudo bibliométrico nos anais do congresso brasileiro de custos. Vitória da conquista -BA, 2018.

SILVA, V. P.; PANNONI, F. D. Estruturas de Aço para Edifícios: Aspectos Tecnológicos e de Concepção. São Paulo: Editora Blucher, 2020.

SIMÕES, E. P. Auditoria interna: contextualização teórica e aplicações em empresas comerciais brasileiras. Entrepreneurship, Jul a Dez - v.4 - n.2, 2020.

SOUSA, F. I. A.; COSTA, A. F. Gestão de liderança e o comportamento pessoal no ambiente organizacional em setores industriais: Uma revisão de literatura. Faculdade Unifametro Maracanaú, Maracanaú, p. 1-26, 2020.

SOUZA, D. R. Qual é a importância do controle de estoque nas indústrias no polo industrial de Manaus? Faculdades IDAAM, 2017.

WENDLING, M. Estilos de liderança e sua efetividade nas empresas: Um estudo de caso. Universidade Federal do Rio Grande do Sul, 2017.

ZGIERSKI, C. C. Sistemática de controle de estoque: estudo de caso na auto elétrica Grimm. Universidade Regional do Noroeste do Estado do Rio Grande do Sul, Santa Rosa, 2016.

ZORZO, A. Gestão de produtos e operações. São Paulo: Pearson Education do Brasil, 2015.

ZUCATTO, L. C. et al. Pesquisa básica e pesquisa aplicada: uma análise da produção científica sobre Covid-19. Research, Society and Development, v. 9, n. 11,2020

Enviado: Setembro, 2021

Aprovado: Novembro, 2021.

RC: 100860

Disponível em:

https://www.nucleodoconhecimento.com.br/contabilidade/instrumento-de-adequacao 